\title{
Die Haftung der Magistrate für die Vormundsbestellung im römischen Recht $^{1}$
}

\section{EMESE ÚJVÁRI}

In der römischen Gesellschaft war es - wegen des relativ niedrigen Durchschnittsalters - von großer Bedeutung, für die verwaisten Unmündigen (die also nicht unter der Familiengewalt eines Hausvaters standen) geeignete Vormünder zu finden. Die Problematik der (oft nötigen) amtlichen Vormundsbestellung erschien in der römischen Gesellschaft als ein eigenartiges Grenzgebiet zwischen dem Privatrecht und dem öffentlichen Recht. Die Regeln der Haftung der Beamten für die Vormundsbestellung bedeuten höchstwahrscheinlich die ersten eindeutigen Spuren davon, dass die Akten der Beamten gegebenenfalls auch privatrechtliche Konsequenzen haben konnten. In der Abhandlung wird diese Problematik mithilfe der fachgerechten Methoden und Mittel der römischrechtlichen Forschungen untersucht.

Schlüsselwörter: römische Vormundschaft, Vormundsbestellung, magistratische Haftung, Munizipalmagistrate, actio subsidiaria

\section{A magistratusok gyámrendelésért való felelössége a római jogban}

A római társadalomban - a viszonylag alacsony átlagéletkor miatt - kiemelkedö jelentösége volt annak, hogy az árván maradt serdületlenek (akik tehát nem álltak apai hatalom alatt) megfelelö gyámot kapjanak. Az esetek jelentös részében szükségessé vált hivatali gyámrendelés problémaköre a közjog és a magánjog egy sajátos határterületeként jelent meg a római társadalomban. A hivatalnokok gyámrendeléssel kapcsolatos felelösségének szabályai talán az elsö kézzelfogható nyomát jelentik annak, amikor a hivatali hatáskörben végzett aktusoknak magánjogi konzekvenciái lettek. A tanulmány ezt a kérdéskört járja körül a római jogi kutatások sajátos módszerével és eszközrendszerével.

Kulcsszavak: római gyámság, gyámrendelés, magistratusi felelősség, municipális magistratusok, actio subsidiaria

1 Das Werk wurde im Rahmen des Prioritätsprogramms mit Identitätsnummer KÖFOP-2.1.2-VEKOP-15-2016- 00001 mit dem Titel „Entwicklung des Öffentlichen Dienstes gerichtet auf Gute Regierungsführung “ im Ludovika Forschungswerkstatt im Auftrag von Nationale Universität für Öffentlichen Dienst fertiggestellt. 


\section{Das Wesen der römischen Vormundschaft}

Die Vormundschaft war in Rom ein genauso wichtiges Rechtsinstitut, wie in unseren Tagen. Da in Rom in der Regel auch die sui iuris Frauen selbst unter Vormundschaft stehen mussten, ${ }^{2}$ hatte im Falle eines Unmündigen schon der Tod des pater familias die Folge, dass er (oder sie) einen Vormund brauchte, auch wenn seine Mutter noch im Leben war. Während für die Erziehung und Betreuung des Unmündigen in erster Linie weiterhin seine Mutter (oder eventuell seine Großmutter) zu sorgen hatte, war für die Vermögensverwaltung grundsätzlich sein Vormund verantwortlich, ${ }^{3}$ und er musste der Mutter aus dem Vermögen des Mündels für seinen Unterhalt alimenta zahlen. ${ }^{4}$

Die Juristen versuchten schon relativ früh, den Begriff der Vormundschaft möglichst exakt zu definieren. So bestimmte zum Beispiel - sich an Servius Sulpicius Rufus berufend, der im 1. Jahrhundert v. Chr. lebte - Iulius Paulus die Vormundschaft im 1. Jahrhundert n. Chr. ${ }^{5}$

D.26,1,1pr.

Paulus 38 ad ed.

„Tutela est, ut Servius definit, vis ac potestas in capite libero ad tuendum eum, qui propter aetatem sua sponte se defendere nequit, iure civili data ac permissa."

„Die Vormundschaft ist, wie Servius definiert, die Macht und Gewalt über einen freien Menschen, die vom Zivilrecht gegeben und gewährt wird, um den zu schützen, der sich wegen seines Alters nicht selbst verteidigen kann."

Die Macht und Gewalt (vis ac potestas) des Vormundes über das Mündel und sein Vermögen war am Anfang beinahe unbegrenzt, da die Vormundschaft nicht nur dem Interesse des Mündels diente, sondern zugleich auch dem Interesse des Vormundes, weil meistens der nächste Erbe des Mündels zum Vormund berufen wurde. Mit der Zeit trat aber allmählich das Interesse des Mündels in den Vordergrund. Die Macht und Gewalt des Vormundes wurde begrenzt, sie wurde zugleich durch die fides ge-

2 Es ist in der Literatur umstritten, wie lange die sui iuris Frauen in Rom unter Vormundschaft stehen mussten. Einige meinen, dass diese Praxis schon während des Prinzipats immer seltener wurde (vgl. KaSer 1971, 367; KASER- KNÜTel-LohSSe 2017, 381; BenedeK-PóKeCZ KovÁCs 2017, 161-162). Andere sind aber der Meinung, dass bis zum 4. Jahrhundert $\mathrm{n}$. Chr. in der Regel jede sui iuris Frau einen Geschlechtsvormund bedarf (vgl. MolNÁR-JАKАВ 2015, 165). Einen vermittelnden Standpunkt scheint zu vertreten: FöLDI-HAMza 2016, 263.

3 Kaser 1971, 360-366; Földi-Hamza 2016, 263; BenedeK-PóKecz Kovács 2017, 164-165; C.5, $49,1,1$.

4 Krause 1995, 98-99; Widauer 2014, 166.

5 ЈАКАв 2017a, 204; ЈАКАВ 2017b, 200.

6 Übersetzung: KNÜTEL et al. 2005, 343. 
mildert, und die Ausübung dieser Macht wie auch die Vermögensverwaltung wurde unter Kontrolle gesetzt. ${ }^{7}$

Der Vormund war (mit Ausnahme der archaischen Zeit) zwar verpflichtet, über seine Vermögensverwaltung Rechenschaft zu geben, und mehrere Klagen und andere Rechtsmitteln dienten dem Zweck, seine pflichtmäßige Vermögensverwaltung zu sichern, kam es trotzdem oft vor, dass der Vormund einen Teil des Mündelvermögens rechtswidrig enteignete, oder die Geschäfte des Mündels einfach aus Fahrlässigkeit vernachlässigte. ${ }^{8}$

Das gewesene Mündel hatte zwar nach der beendeten Vormundschaft die Möglichkeit einer Klage, der actio tutelae, mit der ervon seinem Vormund Rechenschaft über seine Vermögensverwaltung, die Herausgabe des Mündelvermögens, sowie den Ersatz der rechtswidrig zugefügten Schäden verlangen konnte, ${ }^{9}$ konnte es trotzdem leicht vorkommen, dass das Vermögen des verurteilten Vormundes nicht genug war, die Schäden des Mündels zu ersetzen. Das Mündel konnte zwar die Möglichkeit haben, die eventuellen Mitvormünder oder die Bürgen des Vormundes zu verklagen, gab es aber weiterhin keine Garantie dafür, dass das Mündel dadurch einen vollen Schadensersatz erhalten konnte. ${ }^{10}$ Deswegen konnte die Frage entstehen, ob - als ultima ratio - eventuell auch die Magistrate dafür haften müssten, wenn sie (am Anfang der Vormundschaft) für das Mündel keine geeignete Person als Vormund bestellt hatten, und deswegen selbst indirekt für die Schäden verantwortlich waren, die aus der treuwidrigen Vermögensverwaltung des Vormundes entstanden.

Es ist zwar wegen der niedrigen Zahl der einschlägigen Quellen fraglich, ob im Allgemeinen die betroffenen Privatpersonen überhaupt die Möglichkeit hätten, die (ehemaligen) Magistrate ${ }^{11} \mathrm{zu}$ belangen, wenn die Magistrate ihnen Schäden zugefügt hatten, oder gegen sie irgendein Delikt begangen hatten, ${ }^{12}$ betreffend

7 JаKAв 2017a, 205; JAKAв 2017b, 201; KASER- KNÜtel-LohSSE 2017, 375; Földi-HamZa 2016, 262; Kruse 2017, 176; Chevreau 2017, 191.

8 Kaser 1971, 360-366; Földi-Hamza 2016, 263; BenedeK-PóKeCz KovÁcs 2017, 154; MOLNÁR-JAKAB 2015, 164-165.

9 Vgl. KaSER 1971, 365-366.

10 Vgl. KASER 1971, 364-366.

11 Der Begriff von Magistrat (magistratus) bezieht sich in dieser Abhandlung nicht nur auf die durch die Volksversammlung oder durch den Senat gewählten Beamten, sondern (insbesondere bezüglich der Kaiserzeit) gehören die staatlichen und örtlichen Beamten im Römischen Reich in weiterem Sinn zu diesem Begriff.

12 Es gibt in der Literatur mehrere gegenüberstehende Standpunkte bezüglich der Haftung der Magistrate für die Schäden, die sie den Privatpersonen zugefügt haben, bzw. für ihre Delikte. Nach der Meinung von Theodor Mommsen hätten die Privatpersonen die Magistrate belangen können, wenn die Magistrate ihre Rechte verletzten. Er hält dabei die Magistrate mit imperium und die Magistrate mit potestas auseinander: Die Ersteren durften erst nach dem Ablauf ihrer Amtszeit - gegen ihre Wille - belangt werden, die Letztere konnten aber auch während ihrer Amtszeit verklagt werden, auch wenn es bei den kleineren Magistraten häufiger vorkam, dass der Prozess lieber auf die Zeit nach ihrer Amtszeit verschoben wurde, damit sie durch den Prozess nicht der Verwaltung der öffentlichen Angelegenheiten entzogen wurden (vgl. MomMSEN 1887, 698-708). Kunkels Meinung nach beruhe sich aber Mommsens Annahme, dass die Privatpersonen, denen die Magistrate Schäden verursachten, sie nach ihrer Amtszeit in Rahmen 
der Vormundsbestellung gibt es aber zahlreiche Quellen, die bezeugen, dass bestimmte Magistrate dafür hafteten, wenn sie ungeeignete Vormünder oder Sicherheitsleistung für die Mündel bestellt hatten.

Diese Haftung stand teilweise mit der Tatsache in Zusammenhang, dass die Vormundschaft der Unmündigen ab dem 2. Jahrhundert n. Chr. ein zentrales Thema sowohl für die kaiserliche Rechtsschaffung, als auch für die Tätigkeit der kaiserlichen Juristen bildete. ${ }^{13}$ Die Vormundschaft spielte aber auch schon in den früheren Zeiten eine zentrale Rolle im Rechtsleben von Rom. Wahrscheinlich deswegen, weil es oft um die Kontrolle und Verwaltung von bedeutenden Vermögensmassen ging, die für Rom von großer sozialer und wirtschaftlicher Bedeutung waren. ${ }^{14}$

\section{Die zur Vormundsbestellung Befugnis habenden Personen}

Wie es allgemein bekannt ist, gab es in Rom grundsätzlich drei Vormundschaftsarten. In erster Linie hatte der pater familias die Befugnis, in seinem Testament einen Vormund für diejenigen Personen zu ernennen, die seiner Hausgewalt unterworfen waren (tutor testamentarius). ${ }^{15}$ Wenn der Hausvater sich um die Vormundsbestellung für seine unmündigen Kinder nicht kümmerte, wurden im Sinne des Zwölftafelgesetzes die gradnächsten Agnaten ${ }^{16}$ (später, ab der nachklassischen Zeit, die Kognaten) zum gesetzlichen Vormund berufen (tutor legitimus). Schließlich, wenn ein sui iuris Mündel weder einen tutor testamentarius noch einen tutor legitimus hatte, mussten die Magistrate sich um die Vormundsbestellung (tutoris datio) kümmern. ${ }^{17}$

eines Privatverfahrens verklagen konnten, nur auf einer Äußerung von Cicero (Caec. 18), und mangels der diesbezüglichen Quellen, könne diese Annahme nicht bestätigt werden (vgl. KunKeL-Wittmann 1995, 265-272). Éva Jakab folgert aus den einschlägigen Stellen, dass die Privatpersonen die Magistrate oft belangen konnten, wenn die Magistrate ihnen rechtswidrig Schäden zufügten (vgl. Jakab, Éva: Immunitás? Az állam kárfelelösségének történeti gyökereihez [manuskript]). Vielen Dank der Verfasserin für die Zurverfügungstellung des Manuskripts.)

13 NÖRR 2001, 23; JАКАв 2017b, 211. Es ist zu beobachten, dass die Juristen in den Fragmenten, die zum Thema der Vormundschaft gehören, sich auf besonders viele kaiserliche Reskripte berufen (ЈАКАв 2017a, 215; ЈАКАв 2017b, 211).

14 ЈАКАв 2017a, 207. Die Vormundschaft spielte auch wegen des niedrigeren Durchschnittsalters eine wichtige Rolle in Rom. Nach Sallers Feststellungen verloren ungefähr ein Drittel der römischen Bürger noch während ihrer Minderjährigkeit ihre Väter, und ein weiteres Drittel noch vor der Erreichung des 25. Lebensjahres. Die Eigentümer von zirka ein Drittel des Grundstück-Vermögens waren Unmündigen (vgl. SALLER 1994, 181-190).

15 Gai.1,144-150; Iust.Inst.1,13,3-5.

16 Gai.1,155; Iust.Inst.1,15,1.

17 Gai.1,185; Iust. Inst.1,20,1-5; KASER- KNÜTeL-LohSSE 2017, 376-377; FöldI-HAMZA 2016, 262; Molnár-JaKab 2015, 164-165; BenedeK-Pókecz Kovács 2017, 159; TalamanCa 1990, 159-160, 421-424; ÚJVÁRI 2016. 
Die magistratische Vormundsbestellung wurde durch die lex Atilia ${ }^{18}$ ermöglicht. ${ }^{19}$ In Rom mussten ursprünglich der praetor urbanus und die Mehrzahl der Volkstribune über die Vormundsbestellung einen Beschluss treffen. ${ }^{20}$ Seit Claudius hatten auch die Konsuln ${ }^{21}$ und seit Mark Aurel der praetor tutelarius ${ }^{22}$ (später praetor tutelaris genannt) die Befugnis, Vormünder zu bestellen. ${ }^{23}$ Die Zuständigkeit des praetor tutelarius bezog sich nicht nur auf Rom, sondern auch auf die urbica diocesis. ${ }^{24}$ Auch er selbst bestellte Vormünder, aber in erster Linie funktionierte er als Apellationsinstanz. ${ }^{25}$ In der nachklassischen Zeit stand die Befugnis der Vormundsbestellung in Rom und in Konstantinopel dem praefectus urbi zu, der die Vormünder für die viri illustres ${ }^{26}$ im Sinne einer Konstitution aus dem Jahre 389 n. Chr. ${ }^{27}$ nur unter Zuziehung von zehn Senatoren und dem praetor tutelaris bestellen konnte. ${ }^{28}$

In den italienischen Munizipien stand seit der Zeit der divi fratres, also Mark Aurel und Lucius Verus, dem iuridicus regionis die Befugnis der Tutorenbestellung zu. ${ }^{29}$ Im Frag. Vat. 232 steht ausdrücklich, dass der praetor tutelarius solchen Mündeln, deren Vermögen sich in den regiones der iuridici befindet, keine Vormünder bestellen darf, weil er sich nicht in die Zuständigkeit der iuridici einmischen darf. Daraus könne nach der Meinung von Simshäuser darauf gefolgert werden, dass die Befugnis der Vormundsbestellung in den Regionen der iuridici - aufgrund des einfachen Vorschlags der duumviri ${ }^{30}$ - nur den iuridici zustand. ${ }^{31}$

18 Die Entstehung des Gesetzes kann auf 210 v. Chr. datiert werden (vgl. NörR 2001, 2; KASERKNÜTEL-LOHSSE 2017, 377). Nach Grelles Meinung bildeten die großen Menschenverluste des 1. und 2. punischen Krieges den Grund für den Erlass dieses Gesetzes (GrelLE 2006, 413).

19 Vgl. GuZMán 1976, 27-131.

20 Gai.1,185; Iust. Inst.1,20,pr.; Fiebiger-Liebenam 1905, 1835.

21 Suet. Claud. 23,2; SaChers 1948, 1512-1513; Pókecz KovÁcs 2015a, 104; Pókecz Kovács 2015b, 100.

22 Frag. Vat. 244.

23 KaSer-KNütel-Lohsse 2017, 377; Kaser 1971, 357; Benedek-PóKeCZ KovÁcs 2017, 159; Talamanca 1990, 160; Galaboff 2016, 137-138; Nörr 2001, 20, 31; Kruse 2007, 351.

24 Die urbica dioecesis war der bis zu den 100. Meilensteinen von Rom reichende Zuständigkeitsbereich (vgl. SIMSHÄUSER 1973, 251).

25 SACHERs 1948, 1513.

26 Vir clarissimus war ein Rangtitel der Angehörigen des Senatorenstandes in der Kaiserzeit. Seit $365 \mathrm{n}$. Chr. wurden aus den viri clarissimi die viri spectabiles und die viri illustres hervorgehoben (vgl. Ziegler-SONTHEIMER 1979, 1293).

27 C.5,33,1pr.

28 Kaser-KnÜtel-Lohsse 2017, 377; TAlamanCa 1990, 160; Iust. Inst.1,20,4; SACHERs 1948, 1515; GalabofF 2016, 184.

29 Frag. Vat.205, 232, 241; In D.26,5,28 steht der iudex wahrscheinlich statt des iuridicus (vgl. SaChers 1948, 1514; Galaboff 2016, 184). Das Amt der iuridici wurde von Mark Aurel im Interesse der effektiveren Rechtssprechung zustande gebracht (vgl. PóKECz KovÁcs 2016, 125). Die iuridici waren kaiserlichen Beamten, sie wurden von dem Kaiser ernannt, ihre Amtsdauer hing von dem Wille des Kaisers ab, und ihre Gerichtsgewalt leitete sich von der Gerichtsgewalt des Prinzeps her (vgl. SimSHäUSER 1973, 241).

30 KASER 1971, 357.

31 SIMSHÄUSER 1973, 245. 
Eck ist aber der Meinung, dass die Zuständigkeit der iuridici die Befugnis der tutoris datio der magistratus municipales nicht ganz ausgeschlossen habe, sondern Letztere dadurch nur begrenzt worden sei. Die iuridici hätten insbesondere in dem Fall sich um die Vormundsbestellung kümmern müssen, wenn dabei die Grenzen einer italienischen Gemeinde überschreiten werden mussten. So zum Beispiel in dem Fall, wenn der Vormund nicht aus derselben Gemeinde stammte, wie das Mündel, oder wenn das Vermögen des Mündels in verschiedenen Gemeinden zu finden war. In solchen Fällen hätten aber die magistratus municipales dem iuridicus helfen müssen, da sie verpflichtet waren, die potenziell geeigneten Vormünder in den Nachbargemeinden aufspüren, und den iuridicus von den möglichen Personen benachrichtigen. ${ }^{32}$

In den Provinzen war die Vormundsbestellung im Sinne der lex Iulia et Titia - welches Gesetz die tutoris datio in Italien und in den Provinzen regelte ${ }^{33}$ - Aufgabe des proconsul und des praeses provinciae. ${ }^{34}$ Der Statthalter konnte aber die Aufgabe der Vormundsbestellung an die untergeordneten Beamten delegieren. ${ }^{35}$

Der Statthalter wird in den Quellen oft als "qui ei provinciae praeierit" es ist anzunehmen, dass schon die lex Iulia et Titia diesen Ausdruck enthielt. ${ }^{37}$

Um die Frage zu beantworten, ob dieser Ausdruck sich nur auf den Statthalter, oder eventuell auch auf andere Personen bezog, kann das unterstehende Ulpian-Fragment behilflich sein ${ }^{38}$ in dem hinsichtlich der tutoris datio die folgende Aufzählung zu lesen ist:

D. $26,5,1$ pr. -2 .

Ulpianus 39 ad sab.

„(pr.) Sive proconsul sive praeses sive etiam praefectus Aegypti sive proconsulatum optineat provinciae vel temporis causa praeside defuncto vel quia ipsi provincia regenda commissa est, tutorem dare poterit.

(1) Legatus quoque proconsulis ex oratione divi Marci tutorem dare potest.

32 ECK 1979, 258-259.

33 NÖRR 2001. Diese waren wahrscheinlich zwei Gesetze. Nörr datiert die Entstehung der lex Titia auf 31. v. Chr. (vgl. Nörr: SZ. 118., 2.)

34 Gai.1,185; Iust. Inst.1,20,pr.; KASER-KNÜTEL-LOHSSE 2017, 377; NÖRR 2001, 29; BENEDEKPókecz Kovács 2017, 159; Talamanca 1990, 160; Sachers 1948, 1513; Sciuto 2007, $350,390$. Als praeses wurden ab dem 2. Jahrhundert die Provinzstatthalter genannt (vgl. PókECz KovÁCS 2016, 128).

35 Sachers 1948, 1514, Fiebiger-Liebenam 1905, 1835; Galaboff 2016, 184.

36 Fr. 5 col. I lex Ursonensis (Rekonstruktion aufgrund: CRAwFORD 1996, 411); c. 80 lex Irnitania.

37 NÖrR 2001, 29; Galaboff 2016, 150.

38 GalabofF 2016, 150. 
(2) Quod autem permittitur tutorem dare provinciae praesidi, eis tantum permittitur, qui ${ }^{\wedge}$ cui $^{\wedge}$ sunt eiusdem provinciae vel ibidem domicilium habent."

Wie Ulpian schreibt, kann der proconsul, der praeses provinciae, der praefectus Aegypti und der procurator, der das Amt eines proconsul in einer Provinz ausübt, entweder zeitweilig nach dem Tod des Statthalters, oder weil ihm die Verwaltung der Provinz übertragen wurde, Vormünder bestellen. Im Sinne einer Senatsrede von Mark Aurel ist auch dem legatus des proconsul die Vormundsbestellung gestattet. Der Statthalter darf aber nur für solche Personen Vormünder bestellen, die Angehörige seiner Provinz sind, oder dort ihren Wohnsitz haben. ${ }^{39}$

Auch im nächsten Fragment geht es um die Vormundsbestellung:

D.1,20,2

Ulpianus 39 ad sab.

„Iuridico, qui Alexandriae agit, datio tutoris constitutione divi Marci concessa est."

Ulpian berichtet in dieser Stelle davon, dass dem iuridicus, der in Alexandria tätig ist, im Sinne einer Konstitution von Mark Aurel, die Vormundsbestellung gestattet ist.

Den in der vorherigen Stelle erwähnten Beamten (proconsul, praeses und praefectus Aegypti) stand das Recht der tutoris datio aller Wahrscheinlichkeit nach schon im Sinne der lex Iulia et Titia zu. Der iuridicus Alexandriae und der legatus proconsulis hatten aber die Befugnis der Vormundsbestellung nicht direkt aufgrund der lex Iulia et Titia, sondern erst dank kaiserlicher Konstitutionen (constitutio, oratio divi Marci) ${ }^{40}$

In den lateinischen Munizipien und römischen Kolonien übten am Ende der klassischen Zeit und in der nachklassischen Zeit neben dem Statthalter sowohl die magistratus municipales als auch der defensor civitatis ${ }^{41}$ aufgrund der munizipalen Verfassung der betroffenen Stadt die tutoris datio aus. ${ }^{42}$ (Unter dem Begriff

39 NÖRR 2001, 29-30.

40 NÖRr 2001, 29-30; Galaboff 2016, 150-151.

41 Vom defensor civitatis (plebis) siehe: Ziegler-SONTHEIMER, 1979, 1422-1423.

42 Vgl. Erman 1894, 241-255, 247-253; TalamanCA 1990, 160; GlücK 1829, 411. 
der magistratus municipales versteht man die duumviri ${ }^{43}$ und quattuorviri ${ }^{44}$ der gegebenen Munizipien oder Kolonien. $)^{45}$

Aus dieser Hinsicht sind die lex municipi Irnitani und die lex municipi Salpensani, die munizipalen Verfassungen von der hispanischen Irni und Salpensa aus dem Jahre 90 n. Chr., die - mit Ausnahme der Ortsnamen - inhaltlich beinahe identisch waren, wichtig für uns. ${ }^{46}$ Salpensa und Irni waren Munizipien mit lateinischem Recht, die zusammen mit Malaca unter den Flavien den Status „municipium” erhielten. ${ }^{47}$

Im Sinne vom c. 29 lex municipi (Irnitani, Salpensani) ${ }^{48}$ hatten in diesen Städten die magistratus municipales, also die duumviri, das Recht der Vormundsbestellung, ${ }^{49}$ und sie haben ihre Entscheidungen entweder "de omnium collegarum sententia", also zusammen mit ihren Kollegen, oder "ex decreto decurionum”, also aufgrund des Beschlusses der decuriones getroffen. ${ }^{50}$

Ähnlich steht es im c. 109 lex Coloniae Genetivae Iuliae (lex Ursonensis), ${ }^{51}$ welches Gesetz (aus dem Jahre 44 v. Chr.) die Verfassung der von Caesar in Hispania begründeten Colonia Genetiva Iulia Urbanorum, anders genannt Colonia Ursonensis war. Im Sinne des Gesetzes konnten nicht nur die Frauen, sondern auch die Unmündigen bei den duumviri die Vormundsbestellung beantragen, und konnten auch den gewünschten Vormund bezeichnen..$^{52}$

Aufgrund des c. 109 lex Ursonensis und des c. 29 lex municipi (Irnitani, Salpensani) kann also darauf gefolgert werden, dass auch die örtlichen Verfassungen bezüglich der tutoris datio Bestimmungen enthielten. In welchem Verhältnis die örtlichen Zuständigkeiten der Munizipalmagistrate mit den zentralen Zuständigkeiten der Statthalter standen, war aber nicht einmal in der Spätkaiserzeit eindeutig, obwohl die Quellen aus dieser Zeit relativ umfangreich erhalten blieben. Es ist wahrscheinlich, dass - wie es auch für die anderen Angelegenheiten charakteristisch

43 Die duoviri waren die höchstrangigen Beamten der römischen oder lateinischen Munizipien und Kolonien, die den römischen Konsuln entsprachen. Jährlich wurden zwei duoviri gewählt, ihre ganze Bezeichnung lautete: duoviri iure dicundo (vgl. HAVAS-NÉMETH-SzABó 2001, 203; SCHUberT, 352; Ziegler-SONTHEIMER, 1979, 880-881).

44 Quattuorviri wurden die vier gewählten Beamten der Munizipien. Zum Kollegium der quattuorviri gehörten die zwei höherrangigen quattuorviri iure dicundo und die zwei quattuorviri aediles (Vgl. Havas-Németh-Szabó 2001, 182-183).

45 Rudorf 1834, 159; Ziegler-SONTHEIMER 1979, 880-881.

46 NÖRR 2001, 2.

47 Vgl. Havas-Németh-Szabó 2001, 313-314; Illés 2007, 5-7; Grelle 2006, 422-425.

48 Textrekonstruktion: GonZÁles-Crawford 1986, 147-243. Zu der lex Irnitana siehe noch: Panero Oria 2011, 973-996; Lamberti 1993, 1993.

49 Vgl. Sachers 1948, 1514; Kaser 1971, 357; Fiebiger-Liebenam 1905, 1835; Galaboff 2016, 184; Mitteis 1908, 390-403, 392-393. Sie dazu: Panero Oria 2011, 973-996.

50 NÖRR 2001, 31, 38-40; GALABOFF 2016, 151. Galaboffs Meinung nach hätten die duoviri den tutor impuberum jedem Fall „ex decreto decurionum” bestellen müssen, den tutor mulierum aber nur dann, wenn es keinen Kollegen gab, oder wenn der Kollege fort war (vgl. GaLABoff 2016, 140-141).

51 Textausgabe: Crawford 1996, Nr. 25, 411. Zu der lex Ursonensis vgl.: Gómez-Iglesias CASAL 1997, 247-266; JanZsó-Szabó 2009, 21-50.

52 NÖRR 2001, 2-4. 
war - die Zuständigkeit des Statthalters mit den örtlichen Zuständigkeiten der Munizipalmagistrate konkurrierte..$^{53}$

Es ist aber bestritten, ob auch in den römischen Munizipien ${ }^{54}$ den magistatus municipales im Allgemeinen das Recht der tutoris datio zustand..$^{55}$

Mommsen vertritt den Standpunkt, dass sowohl aus dem D.27,8,1,156 als auch daraus, dass in Gai.1,185 und Ulpiani Liber Singularis 11,18 die magistratus municipales unter den zur Vormundsbestellung berechtigten Personen nicht erwähnt werden, darauf gefolgert werden könne, dass ihnen in den römischen Munizipien das Recht der tutoris datio nicht gewährt worden sei. Nach seiner Meinung könne diese Folgerung mit den zahlreichen Hinweisen in den Quellen, ${ }^{57}$ die das Recht der tutoris datio der magistratus municipales doch bestätigen, mithilfe der Annahme im Einklang gebracht werden, dass aufgrund der lex Iulia et Titia in den Provinzen ursprünglich jeder Vormund von den Statthaltern bestellt worden sei, und diese Vormundsbestellung normalerweise aufgrund der Vorschlag (nominatio) der betroffenen magistratus municipales erfolgt gewesen sei. Später sei aber in Angelegenheiten von niedriger Bedeutung die Vormundsbestellung den magistratus municipales ermöglicht worden, aber die formelle datio sei virtuell nominatio geblieben. ${ }^{58}$

Karlowa bestreitet aber die Richtigkeit der Behauptungen Mommsens. Er vertritt nämlich den Standpunkt, dass das Ulpian-Fragment D.27,8,1,1 sich nur auf die römischen Magistrate beziehe, und Gai.1,185 und Ulpiani Liber Singularis 11,18 nur die gesetzlich ermächtigten Magistrate erwähnten, aber die Magistrate, die das ius tutoris dandi durch Senatsbeschlüsse oder kaiserliche Konstitutionen erwarben, wie

53 NÖRR 2001, 60; Siehe noch Mitteis 1908, 396-397.

54 Der Unterschied zwischen den municipia und den coloniae civium Romanorum bestand ursprünglich darin, dass die municipia civium Romanorum in bestimmter Hinsicht als Ergebnis von äußerer Einwirkung zustande kamen, dadurch, dass peregrine Städte in das römische Bürgerrecht aufgenommen wurden. Sie waren autonomen Stadtgemeinden. Demgegenüber waren die coloniae civium Romanorum solche Gemeinden, die von Rom durch eine geschlossene Ansiedlung von römischen Bürgern begründet wurden. Die römischen Bürger, die coloniae gegründeten, konnten ihr volles Bürgerrecht behalten, aber die Kolonien hatten ursprünglich keine Autonomie. Mit der Zeit glichen sich die zwei Städtearten einander immer mehr an, und in der Kaiserzeit gab es keinen Unterschied mehr zwischen ihnen. Zu der Rechtsstellung der römischen Kolonien und Munizipien siehe ausführlicher: SIMSHÄUSER 1973, 35-46.

55 Kaser 1971, 357; Fiebiger-Liebenam 1905, 1834-1835. Rudorff ist der Meinung, dass die tutoris datio den magistratus municipales zustand (vgl. RUdorfF 1832, 354).

56 „Neque praetor neque quis alius, cui tutoris dandi ius est, hac actione tenebitur” (D.27,8,1,1). Im Fragment wird behauptet, dass die actio subsidiaria weder gegen den Prätor, noch gegen jemanden anderen, der zur tutoris datio befugt ist, gegeben wird. Da es durch zahlreiche Quellen bestätigt wird, dass diese Klage gegen die magistratus municipales gegeben wurde, folgert daraus Mommsen darauf, dass das ius tutoris dandi den magistratus municipales nicht zustand (vgl. MoMMSEN 1857, 438-439).

57 Z. Bs. D.26,5,3; D.26,5,19,1; D.50,1,2,5; C.5,34,5; Frag.Vat.191, 247.

58 Mommsen 1857, 438-439. Auch Solazzi bezweifelt das selbständige ius tutoris dandi der magistratus municipales (vgl. Solazzi 1917-1918, 1-24). 
zum Beispiel der consul, der praefectus urbi, und der praetor tutelaris, seien nicht erwähnt. ${ }^{59}$

Er bestreitet weiterhin auch, dass die formelle datio eine virtuelle nominatio gewesen wäre, weil die Quellen ${ }^{60}$ bewiesen, dass es einen eindeutigen Unterschied dazwischen gegeben habe, ob die Magistrate den Vormund selbst bestellten (datio) oder bezüglich der möglichen Vormünder nur einen Vorschlag machten (nominatio). Karlowa ist aber der Meinung, dass das Vormundsbestellungsrecht des magistratus municipales hinter dem Recht des praeses provinciae gestanden sei, und die Magistrate dieses Recht nur auf Befehl des Statthalters, und nur dann, wenn das Vermögen des Mündels nicht bedeutend war, hätten ausüben können. ${ }^{61}$

Mitteis vertritt demgegenüber den Standpunkt, dass den magistratus municipales das Recht der tutoris datio beweisbar zustand. ${ }^{62}$ Auch die nächste Stelle scheint seine Annahme zu bestätigen: ${ }^{63}$

D. $26,5,3$

Ulpianus 36 ad ed.

"Ius dandi tutores datum est omnibus magistratibus municipalibus eoque iure utimur, sed illum, qui ab eodem municipio vel agro eiusdem municipii est."

Ulpian stellt in dem Fragment fest, dass das Recht der Vormundsbestellung (ius tutoris dandi) jedem magistratus municipales zusteht, aber nur hinsichtlich solcher Vormünder, die aus demselben Munizipium oder derer Territorium stammen.

Fraglich ist es aber, ob das Recht der Vormundsbestellung den örtlichen Beamten auch in den Peregrinen-Gemeinden zustand. In der Literatur wird es vor der Zeit der constitutio Antoniniana hinsichtlich der römischen Bürger meistens bestritten, aber bezüglich der Peregrinen wird es im Allgemeinen bejaht. ${ }^{64} \mathrm{Ob}$ das selbstständige ius tutoris dandi nach der constitutio Antoniniana den örtlichen Beamten zustand, ist in der Literatur ebenfalls strittig. Einige bejahen es ${ }^{65}$ andere meinen aber, dass die örtlichen Beamten die Vormundsbestellung nur aufgrund einer Delegation ausüben durften ${ }^{66}$ Es ist aber anzunehmen, dass auch wenn das selbstständige ius tutoris dandi der magistratus municipales tatsächlich gegeben war, es schon vor Iustinians Zeit wegen der kaiserlichen Bürokratie wieder entfallen ist. ${ }^{67}$

59 Karlowa 1855, 596.

60 D.27,8,1,2-3.

61 Karlowa 1855, 596. Ähnlich auch Fiebiger-Liebenam 1905, 1835.

62 Mitteis 1908, 390-392; Erman 1894, 248.

63 NÖRR 2001, 22.

64. Mitteis 1908, 393.

65 Sciuto 2007, 370-371; Mitteis 1908, 396.

66 Kruse 2017, 181-182.

67 Mitteis 1908, 401; Erman 1894, 247-253. 


\section{Die Verpflichtungen der Magistrate bezüglich der Vormundsbestellung}

Die Magistrate mussten sich dann um die Vormundsbestellung kümmern, wenn jemand, der einen Vormund brauchte, keinen hatte, oder wenn das Vorhandensein eines Vormundes ungewiss war. Die Vormundsbestellung musste beantragt werden, wozu jeder das Recht hatte. Einige nahe Verwandten (so besonders die Mutter des Mündels) hatten aber unter Strafdrohung die Pflicht, die tutoris datio zu beantragen. ${ }^{68}$

Die Behörden prüften zuerst, ob die Vormundsbestellung tatsächlich nötig war, ${ }^{69}$ ob sie dafür zuständig waren, ${ }^{70}$ und eventuell, ob die gegebene Person geeignet (idoneus) für die Vormundschaft war..$^{71}$ Die Vormünder, bezüglich deren es geprüft wurde, ob sie geeignet waren, wurden meistens tutores ex inquisitione dati genannt, die Vormünder, die ohne solche Prüfung bestellt wurden, nannte man tutores sine inquisitione oder simpliciter dati.

Die Magistrate hatten sich aber oft nicht nur um die Bestellung von geeigneten Vormündern zu kümmern, sondern auch um die richtige Vermögensverwaltung. Sie versuchten die Magistrate meistens dadurch zu sichern, dass sie am Anfang der Vormundschaft den Vormund zu einer mit Bürgen gesicherten Stipulation, zur satisdatio/cautio rem pupilli salvam fore verpflichteten. ${ }^{72}$ Der Vormund versprach in dieser Stipulation, dass er das Vermögen des Mündels richtig verwalten werde, und er alles in Zusammenhang mit der Vormundschaft tun werde, was die bona fides verlangt. ${ }^{73}$

$\mathrm{Zu}$ dieser satisdatio war aber nicht jeder Vormund verpflichtet. Die Römer meinten, dass die in dem Testament ernannten Vormünder keine Sicherheit zu leisten brauchen, da der pater familias von ihrer Ehrlichkeit überzeugt war. Im Allgemeinen waren die von den höheren Magistraten (insbesondere von dem Konsul, Prätor und Statthalter) bestellten (und hinsichtlich ihrer Vertrauenswürdigkeit überprüften) Vormünder auch nicht zur Sicherheitsleistung verpflichtet. ${ }^{74}$ So mussten in der Regel die gesetzlichen Vormünder, die von den magistratus municipales bestellten Vormünder ${ }^{75}$ und die von höheren Magistraten sine inquisitione bestellten Tutoren die satisdatio versprechen. ${ }^{76}$

68 D.26.6.1; D. 26,6,2,1-2; KASER-KNÜTEL-LOHSSE 2017, 377; KASER 1971, 358; SAChERS 1948, 1518-1519; GaLABOFF 2016, 181-183.

69 D. $26,3,7,1$.

70 Vgl. SACHERS 1948, 1515-1517.

71 D.26,2,18; D.26,7,3,3; SACHERS 1948, 1519-1520.

72 Gai.1,119. Földi-HAMZa 2016, 263. Sie dazu auch: CARBone, 2017.

73 D.46,6,11; SAChers 1948, 1569-1571; Lenel 1927, 540-541; KASER-KNÜTEL-LohsSE 2017, 380; KASER 1971, 365; CARBone 2014, 1.

74 Gai.1,200; C.5,42,4.

75 D.26,4,5,1; D.26,3,5; Gai.1,199; SACHERs 1948, 1569-1570; KASER-KNÜTEL-LohSSE 2017, 380; KaSer 1971, 365; GalabofF 2016, 92.

76 C.5,59,5,pr; LeVY 1916, 36-37; GlüCK 1829, 357; KüBlER 1918, 185-186. Zum Thema siehe noch: Carbone 2014, 15-23; Carbone 2007, 247-268, 261-262. 
Die Klage aus der satisdatio/cautio rem pupilli salvam fore, also die actio ex stipulatu und die Klage aus der Vormundschaft selbst, die actio tutelae, waren praktisch gleichwertig, wie es durch die folgenden Stellen auch bestätigt wird:

D. $46,6,9$

Pomponius 15 ad sab.

„Cum pupillus a tutore stipulatur rem salvam fore, non solum quae in patrimonio habet, sed etiam quae in nominibus sunt ea stipulatione videntur contineri: quod enim in tutelae iudicium venit, hoc et ea stipulatione continetur."

Im Sinne des Fragments, wenn der Vormund dem Mündel in einer Stipulation verspricht, dass sein Vermögen unversehrt bleiben wird, scheint die Stipulation sich nicht nur darauf zu beziehen, was das Vermögen enthält, sondern auch darauf, was in Forderungen besteht. Da auch diese Stipulation enthält alles, was in die Vormundschaftskalge kommt. Pomponius stellt also in der Quelle fest, dass sowohl die actio tutelae, als auch die actio ex stipulatu sich nicht nur auf die Vermögensgegenstände, sondern auch auf die Forderungen beziehen, die zum Mündelvermögen gehören.

D. $46,6,11$

Neratius 4 membr.

„Cum rem salvam fore pupillo cavetur, committitur stipulatio, si, quod ex tutela dari fieri oportet, non praestetur: nam et si salva ei res sit, ob id non est, quia, quod ex tutela dari fieri oportet, non solvitur."

In der Stelle wird festgestellt, dass das Stipulationsversprechen gebrochen wird, wenn dem Mündel Sicherheit bestellt wurde, dass sein Vermögen unversehrt bleibt, und das, was in Folge der Vormundschaft gegeben oder getan werden musste, nicht geleistet wurde. Denn wenn auch das Vermögen unversehrt ist, ist es doch nicht, weil das, was in Folge der Vormundschaft gegeben oder getan werden musste, nicht geleistet wurde.

Die zitierten Quellen zeigen also, dass die Vormünder - sowohl im Falle der actio tutelae, als auch als Folge der satisdatio - auch für die Schäden haften mussten, die deswegen entstanden, weil der Vormund etwas versäumte, wozu er aus der Vormundschaft verpflichtet war, auch wenn dadurch das Vermögen des Mündels zwar nicht weniger wurde, aber es entweder eine Forderung verlor, oder sein Vermögen sich nicht so vermehrte, wie es möglich gewesen wäre. 
Durch die satisdatio/cautio rem pupilli salvam fore entstand also eine klagbare Verpflichtung des Vormundes für die richtige Vermögensverwaltung, und er haftete auch für die Schäden, die er fahrlässig dem Mündel zugefügt hatte. Und dem Mündel stand eine actio ex stipulatu gegen den Vormund zu. Diese Klage war praktisch gleichwertig mit der actio tutelae directa, und es wurde durch sie gleichzeitig auch ermöglicht, im Falle der Insolvenz des Vormundes auch dessen Bürgen zu verklagen. ${ }^{77}$

Wenn die Magistrate die Vormünder nicht zur Sicherheitsleistung verpflichteten, obwohl es nötig gewesen wäre, hafteten dafür bestimmte Magistrate dem Mündel subsidiär, und diese subsidiäre Haftung belastete sie selbstverständlich auch dann, wenn sie gar keinen oder keinen geeigneten Vormund bestellten. ${ }^{78}$

\section{Die subsidiär haftenden Magistrate}

Ursprünglich verordnete auf Vorschlag von Trajan ein Senatsbeschluss, dass gegen die magistratus municipales, die die Vormünder vorgeschlagen hatten (nominare), dem Mündel nach der Beendigung der Vormundschaft eine Klage zustehen sollte, wenn die Vollstreckung sowohl gegen seine Vormünder als auch gegen die Bürgen (mindestens teilweise) erfolglos geblieben war: ${ }^{79}$

\section{C.5,75,5: Imperatores Diocletianus, Maximianus}

„In magistratus municipales tutorum nominatores, si administrationis finito tempore non fuerint solvendo nec ex cautione fideiussionis solidum exigi possit, pupillis quondam in subsidium indemnitatis nomine actionem utilem competere ex senatus consulto, quod auctore divo Traiano parente nostro factum est, constitit." (294?)

In der Konstitution geht es darum, dass im Sinne eines Senatsbeschlusses, der unter Trajan entstand, wenn die Vormünder bei der Beendigung der Verwaltung insolvent sind, und das Mündel auch nicht von ihren Bürgen das Ganze beitreiben kann, dem gewesenen Mündel seiner Schadloshaltung wegen eine actio utilis gegen die Magistrate, die die Vormünder nominierten, zusteht.

Seit Hadrian konnte das Mündel auch denjenigen verklagen, der die Aufgabe hatte, die von dem Vormund zu leistende Sicherheit zu bewerten: ${ }^{80}$

\footnotetext{
77 Vgl. SaChers 1948, 1571; Galaboff 2016, 93.

78 Siehe unten.

79 C.5,75,5; D.27,8,2; Levy 1915, 41; Karlowa 1855, 596; NörR 2001, 25-26; RudorfF 1834, 154; SACHERS 1948, 1581; GlüCK 1829, 411; KASER 1971, 367; Rampazzo 2011, 363-378, 373-374; Sciuto 2007, 372-373.

80 Carbone 2014, 127.
} 
D. $27,8,1,8$

Ulpianus 36 ad ed.

„Divus Hadrianus rescripsit etiam in eum, qui electus est ad aestimandas tutorum satisdationes, actionem dandam."

Rudorff meint, dass in der klassischen Zeit in Rom und in Konstantinopel der scriba des praetor tutelaris die Aufgabe hatte, das Vermögen des Mündels einzuschätzen, und aufgrund dieses Inventars die Höhe der satisdatio festzustellen. ${ }^{81}$

Neben den erwähnten Personen stand dem Mündel - in bestimmten Ausnahmefällen ${ }^{82}$ - auch gegen den ordo decurionum (Stadtrat) eine Klage zu:

D.27,8,1pr.

Ulpianus 36 ad ed.

"In ordinem subsidiaria actio non dabitur, sed in magistratus, nec in fideiussores eorum: hi enim rem publicam salvam fore promittunt, non pupilli. Proinde nec nominatores magistratuum ex hac causa tenebuntur, sed soli magistratus. Sed si ordo receperit in se periculum, dici debet teneri eos, qui praesentes fuerunt: parvi enim refert, nominaverint vel fideiusserint an in se periculum receperint: utilis ergo in eos actio competit. Sed si a magistratibus municipalibus tutor datus sit, non videtur per ordinem electus."

Die actio subsidiaria wird - wie Ulpian schreibt - dem Mündel gegen den ordo decurionum in der Regel nicht gewährt, nur gegen den Magistrat. Wenn aber der Stadtrat die Haftung auf sich genommen hat, müssen diejenigen, die bei dem Beschluss anwesend waren, haften. Ulpians Meinung nach macht es keinen Unterschied, ob sie die Vormünder nominiert, für sie verbürgt, oder die Haftung auf sich genommen haben, deswegen muss gegen sie die actio utilis gewährt werden. Wenn aber die magistratus municipales die Vormünder bestellten, ist nicht anzunehmen, dass die Vormünder von dem Stadtrat ausgewählt wurden..$^{83}$

Wie es sich aus dem folgenden Fragment herausstellt, konnten in bestimmten Fällen selbst die decuriones ${ }^{84}$ Vormünder bestellen. In solchen Fällen hafteten nur diejenigen decuriones, die an der Vormundsbestellung teilnahmen: ${ }^{85}$

81 Nov. 94. (Epilogus), Rudorff 1834, 159; SACHers 1948, 1582; GLÜCK 1829, 411, 416-417.

82 NÖrR 2001, 33; SACHERS 1948, 1581.

83 GRelle 2006, 431; GLÜCK 1829, 414.

84 Die decuriones waren in den Gemeinden mit Selbstverwaltung die Mitglieder des Stadtrates, also des ordo decuruionum (HAVAS-NÉMETH-SzABó 2001, 182-183).

SACHERS 1948, 1581. 
D. $26,5,19$ pr.

Paulus 16 ad Plaut.

„Ubi absunt hi, qui tutores dare possunt, decuriones iubentur dare tutores, dummodo maior pars conveniat: ubi non est dubium, quin unum ex se dare possint."

Im Sinne der Stelle, wenn diejenigen, die das Recht der Vormundsbestellung haben, abwesend sind, werden die decuriones dazu ermächtigt, wenn die Mehrheit sich einig ist. Sie können einen Vormund auch aus ihrer Mitte bestellen.

Um die nominatio tutoris durch den decuriones handelt es sich in der folgenden Stelle: ${ }^{86}$

\section{C.5,33,1,5: Imperatores Valentinianus, Theodosius, Arcadius}

"In provinciis autem curiales in nominandis tutoribus et curatoribus clarissimarum personarum exhibeant debitam cautionem, et discriminis sui memores cognoscant indemnitati minorum obnoxias etiam suas deinceps esse facultates." (389)

Im Sinne der Konstitution haben sich die curiales in Zusammenhang mit der Vormundsbestellung für die personae clarissimae um die geeignete Sicherheitsleistung (satisdatio) zu kümmern. Und sie müssen daran denken, dass sie mit ihrem eigenen Vermögen für den Ersatz der eventuellen Schäden des Mündels einzustehen haben. ${ }^{87}$

Interessanterweise belastete aber diese subsidiäre Haftung die höheren Magistrate, denen das ius tutoris dandi in erster Linie zustand, nie. So wurde dem Mündel die actio subsidiaria weder gegen den Stadtpräfekten, noch den Prätor, den Konsul oder den Statthalter gewährt, ${ }^{88}$ wie es auch bei Iustinian ausdrücklich zu lesen ist: ${ }^{89}$

Iust. Inst.1,24,4

„Neque autem praefectus urbis neque praetor neque praeses provinciae neque quis alius cui tutores dandi ius est, hac actione tenebitur, sed hi tantummodo qui satisdationem exigere solent."

Es ist also feststellbar, dass für die Vormundsbestellung nur die Beamten von niedrigerem Rang hafteten, wie zum Beispiel der scriba, die magistratus municipales, oder

\footnotetext{
86 NÖRR 2001, 60.

87 Grelle meint, dass die Begrenzung der Wirkung der Konstitution nur auf die personae clarissimae die Folge einer Interpolation sei (vgl. Grelle 2006, 437). Auch Rudorff hält die Stelle für interpoliert (vgl. RudorfF 1834, 161). Siehe auch: TAROzzi 2013, 107-126, 121-124.

88 RudorfF 1834, 161; Karlowa 1855, 596; GLÜCK 1829, 412.

89 Vgl. auch: C.5,33,1pr.
} 
eventuell die Mitglieder des ordo decurionum,,$^{90}$ die höheren Magistrate hafteten aber weder in Rom, noch in Konstantinopel, noch in den Provinzen dafür. ${ }^{91}$

\section{Die Voraussetzungen der subsidiären Haftung der Magistrate}

Die Voraussetzungen der subsidiären Haftung der Magistrate und gleichzeitig der Gewährung der sogenannten actio subsidiaria ${ }^{92}$ dem Mündel waren die Folgende: A. Da die Magistrate für die Vormundsbestellung nur subsidiär hafteten, konnte das gewesene Mündel sie nur dann verklagen, wenn es für seine Schäden, die aus der Verwaltung des Vormundes entstanden, weder von dem Vormund noch von seinen Bürgen einen vollen Ersatz erlangen konnte..$^{93}$

Das wird auch durch die erwähnte Konstitution C.5,75,5 bestätigt, die um denjenigen Senatsbeschluss handelt, der verordnete, dass dem Mündel gegen die magistratus minicipales, die seine Vormünder nominierten, eine Klage zustehen soll, aber nur in dem Fall, wenn die Vormünder bei der Beendigung der Vormundschaft insolvent waren, und das Mündel seine ganze Forderung auch von den Bürgen nicht vollkommen beitreiben konnte.

Auch in der nächsten Konstitution geht es um die subsidiäre Haftung der Nominatoren, also der Personen, die die Vormünder vorgeschlagen haben:

\section{C.5,75,4: Imperator Gordianus}

„Adversus nominatorem tutoris vel curatoris minus idonei non ante perveniri potest, quam si bonis nominati itemque fideiussoris eius nec non collegarum quoque, ad quorum periculum consortium administrationis spectat, excussis non sit indemnitati pupilli vel adulti satisfactum." (242)

Im Sinne der Konstitution kann die Person, die einen untüchtigen Vormund oder Pfleger vorgeschlagen hat, nicht eher belangt werden, als bis in das Vermögen der vorgeschlagenen Person und seiner Bürgen, weiterhin seiner Kollegen, die die Verantwortung für die Vermögensverwaltung gemeinschaftlich tragen, die Vollstreckung versucht worden ist, um das Mündel oder Minderjährige zu entschädigen, ohne aber die vollkommene Schadloshaltung des Mündels oder des Minderjährigen erreichen zu können.

B. Als weitere Voraussetzung konnte das Mündel die Magistrate nur dann verklagen, wenn sie bei der Vormundsbestellung irgendeinen Fehler begangen hatten.

90 Im Folgenden werden sie in erster Linie als Magistraten bezeichnet.

91 Vgl. SACHERS 1948, 1582.

92 Kaser 1971, 367; Albertario 1912, 3; Levy 1915, 41; Lenel 1927, 321; SaChers 1948, 1581.

93 Vgl. SAChers 1948, 1581; GlÜCK 1829, 406. 
a) Dieser Fehler konnte einerseits dabei bestehen, dass die Magistrate jemandem, der einen Vormund benötigte, überhaupt keinen Vormund bestellten. Dafür hafteten aber die Magistrate nur dann, wenn sie über die Notwendigkeit der Vormundsbestellung Bescheid wussten, weil die Mutter oder jemand Anderer die tutoris datio beantragte: ${ }^{94}$

D. $27,8,1,6$

Ulpianus 36 ad ed.

„Magistratibus imputatur etiam, si omnino tutor vel curator datus non sit: sed ita demum tenentur, si moniti non dederint. Ideo damnum, quod impuberes vel adulescentes medio tempore passi sunt, ad eos magistratus pertinere non ambigitur, qui munere mandato non paruerunt."

Ulpian schreibt, dass die Magistrate auch dafür haften, wenn sie gar keinen Vormund oder Pfleger bestellten. Sie haften aber nur dann dafür, wenn sie dazu aufgefordert wurden. Die Schäden, die dem Mündel oder Heranwachsenden in der Zwischenzeit entstanden, müssen unzweifelhaft die Magistrate ersetzen, die ihre Pflicht, die ihnen übertragen wurde, nicht erfüllten. ${ }^{95}$

b) Wie es schon erwähnt wurde, mussten die Magistrate bei bestimmten Fällen der tutoris datio eine satisdatio/cautio rem pupilli salvam fore von den Vormündern verlangen, die eine durch Bürgschaft gesicherte Stipulation war, wobei die Vormünder versprachen, dass sie das Vermögen des Mündels richtig verwalten werden. ${ }^{96}$ Wenn in solchen Fällen, in denen es nötig gewesen wäre, der Magistrat den Vormund zur satisdatio nicht verpflichtete, und/oder keine Bürgen von ihm verlangte, haftete der Magistrat dafür, ${ }^{97}$ wie es auch durch die nächste Papinian-Stelle bestätigt wird:

\section{D.26,3,5}

Papinianus 11 quaest.

„Tutores a patruo testamento datos iussit praetor magistratus confirmare: hi cautionem quoque accipere debuerunt nec voluntas eius, qui tutorem dare non potuit, neglegentiam magistratuum excusat. Denique praetor non ante decretum interponere potest quam per inquisitionem idoneis pronuntiatis. Unde sequitur, ut, si tutelae

\footnotetext{
94 SACHERS 1948, 1582.

95 GRELle 2006, 431.

96 RudorfF 1834, 169.

97 D.27,8,1,2; D.27,8,1,11; D.27,8,1,17; D.27,8,5; D.50,1,2,5. RudorfF 1834, 169-170; GLÜCK 1829, 412; SACHERS 1948, 1519-1520, 1582.
} 
tempore solvendo non fuerunt, in id, quod de bonis eorum servari non possit, contra magistratus actio decernatur."

In dem Fragment geht es darum, dass der Prätor die Magistrate (einer Stadtgemeinde) angewiesen hat, die Vormünder, die ein Onkel väterlicherseits in seinem Testament für das Mündel ernannt hat, zu bestätigen. Die Magistrate hätten sich um die satisdatio (cautio) kümmern müssen, und nach Papinians Meinung wird ihre Nachlässigkeit durch die Anordnung von dem, der zur Vormundsbestellung nicht ermächtigt war, nicht entschuldigt. Und der Prätor kann seinen Beschluss solange nicht erlassen, bis die Vormünder durch amtliche Untersuchung (per inquisitionem) nicht für geeignet erklärt werden. So, wenn die Vormünder bei Beendigung der Vormundschaft insolvent waren, steht dem Mündel eine Klage gegen die Magistrate zu, mit der das Mündel verlangen kann, was es aus dem Vermögen der Vormünder nicht erlangen konnte. ${ }^{98}$

In Zusammenhang mit dieser Stelle könnte sich die Frage erheben, warum die Magistrate die Vormünder zur Sicherheitsleistung verpflichten mussten, wenn es sich um tutores testamentariae handelte, da - wie es schon früher erwähnt wurde - bei der tutela testamentaria die Vormünder in der Regel nicht zur satisdatio verpflichtet waren, weil es angenommen wurde, dass der Erblasser die Vormünder für seinen Gewaltunterworfenen mit der größten Umsicht aussuchte. Im Sachverhalt passierte aber die Ernennung der Vormünder nicht durch das Testament des pater familias, sondern nur ein Onkel väterlicherseits ernannte auf diese Art Tutoren für das Mündel. So wurde die Sicherheitsleistung seitens der Vormünder nötig, die die Magistrate im Sinne der Anordnung des Prätors auch hätten verlangen müssen. Da die Magistrate diese Anordnung nicht folgten, begingen sie betreffend der Bestätigung (confirmatio) der Vormünder vorwerfbar ein Versäumnis. So mussten sie nach der Beendigung der Vormundschaft für die Schäden, die die Vormünder verursachten, subsidiär haften.

c) Die Magistrate hafteten aber nicht nur dafür, wenn sie überhaupt keine Sicherheitsleistung verlangten, sondern auch dafür, wenn sie untüchtige Vormünder bestellten, oder ungeeignete Bürgen akzeptierten, wie es auch durch die früher zitierte C.5,75,4 bestätigt wird. ${ }^{99}$

C. Wie es aber auch aus den folgenden Stellen sich herausstellt, hafteten die Magistrate nur dann, wenn ihr Versäumnis bei der Vormundsbestellung vorwerfbar war, also wenn sie dabei entweder arglistig oder fahrlässig nicht richtig vorgingen. ${ }^{100}$

Es ist interessant zu beobachten, was für die Haftung der magistratus municipales charakteristisch war, wenn sie selbst die Vormünder auf dem Vorschlag des prae-

98 Vgl. dazu auch MANFredini 1990, 51-60.

99 Siehe noch: D.50,1,2,5; D.27,8,1,3; D.27,8,1,5; D.27,8,1,17; D.50,1,2,5; C.5,75,3; C.5,33,1,5. RudorfF 1834, 170; SACHERS 1948, 1582.

100 RudorfF 1834, 168; SCIUto 2007, 372. 
ses provinciae bestellten, und wie sie in dem Falle hafteten, wenn selbst der praeses provinciae die Vormünder aufgrund des vorherigen Vorschlags (nominatio) der Munizipalmagistrate bestellte:

\section{D. $27,8,1,2$}

\section{Ulpianus 36 ad ed.}

„Si praeses provinciae denuntiare magistratus tantum de facultatibus tutorum voluit, ut ipse daret, videamus, an et quatenus teneantur. Et extat divi Marci rescriptum, quo voluit eos, qui praesidi renuntiant, non perinde teneri atque si ipsi dedissent, sed si deceperunt, gratia forte aut pecunia falsa renuntiantes. Plane si praeses provinciae satis eos exigere iussit, non dubitabimus teneri eos, etiamsi praeses dederit."

\section{D. $27,8,1,3$}

\section{Ulpianus 36 ad ed.}

"Si praeses provinciae nominibus ab alio acceptis ad magistratus municipales remiserit, ut se de nominibus instruant, et perinde instructus dederit tutores: an exemplo eorum qui praetorem instruunt debeant magistratus teneri, quaeritur: utique enim interest, utrum ipsi magistratus nomina electa dederint praesidi an ea, quae ab alio praeses accepit, inquisierint, et puto utroque casu sic teneri, quasi dolo vel lata culpa versati sunt."

D. $27,8,1,5$

Ulpianus 36 ad ed.

"Si curatores fuerunt minus idonei dati, dicendum est teneri magistratus oportere, si ex suggestu eorum vel nominibus ab eis acceptis praeses dederit. Sed et si ad eos remiserit, ut ipsi dent vel post dationem ut exigerent satisdationem, periculum ad eos pertinebit."

Aus den zitierten Ulpian-Stellen geht Folgendes hervor: Wenn der Provinzstatthalter von den Magistraten nur verlangte, ihn über die Vermögensverhältnisse der Vormünder zu benachrichtigen, um nachher selbst die Vormünder zu bestellen, ist es zu prüfen, ob die Magistrate haften, und wenn ja, in welchem Umfang sie haften. In einem Reskript von Mark Aurel wurde es verordnet, dass diejenigen, die dem Statthalter nur einen Auskunft geben, nicht genauso haften, wie sie dann haften würden, wenn sie selbst die Vormünder bestellt hätten, sondern sie müssen nur dann genauso haften, wenn sie den Statthalter getäuscht haben, indem sie ihm aus 
Gefälligkeit oder für Geld falsche Informationen gaben. Wenn aber der Statthalter anordnete, dass sie Sicherheit verlangen sollten, und sie es unterlassen haben, haften sie auch dann, wenn selbst der Statthalter die Vormünder bestellt hat.

Wenn der Statthalter - fährt Ulpian fort - die Namen, die er von einem Dritten erhalten hat, an den Munizipalmagistraten weitergeleitet hat, um von den genannten Personen Auskunft zu erhalten, und der Statthalter nach der Erhaltung dieser Auskunft, diese Personen als Vormünder bestellt hat, stellt sich die Frage, ob die Munizipalmagistrate auf solche Weise, wie diejenigen die dem Prätor Auskunft geben, haften müssen. Es ist nämlich ein großer Unterschied, ob die Magistrate selbst die Namen ausgesucht haben, und dem Statthalter dann weitergegeben haben, oder sie solche Namen überprüft haben, die der Statthalter von einem Dritten erhalten hat. Nach der Meinung von Ulpian müssen sie aber in beiden Fällen nur dann haften, wenn sie arglistig (dolus) oder grob fahrlässig (culpa lata) verfahren sind.

Wenn ungeeignete (minus idonei) Pfleger bestellt wurden, müssen die Magistrate haften, wenn der Statthalter aufgrund ihres Berichts, oder nachdem er ihre Namen von den Magistraten erhalten hat, die Pfleger bestellt hat. Die Magistrate müssen aber auch in dem Fall haften, wenn sie die Namen der Kandidaten von dem Statthalter erhalten haben, um die Pfleger selbst zu bestellen, oder von ihnen Sicherheitsleistung zu verlangen.

Aus den vorgeführten Quellen geht es hervor, dass der Statthalter - wenn er selbst die Vormünder (oder Pfleger) bestellte - normalerweise die Magistrate mit der Prüfung der Frage beauftragte, wer für die Vormundschaft/Pflegeschaft geeignet wäre. In solchen Fällen mussten entweder selbst die Magistrate die geeigneten Personen aufspüren, oder ein Dritter hat dem Statthalter bestimmten Personen vorgeschlagen, und der Statthalter hat die Liste der vorgeschlagenen Personen den Magistraten weitergeleitet, damit sie ihre Geeignetheit überprüfen. Wenn die Magistrate in solchen Fällen ungeeignete Vormünder vorgeschlagen haben, oder sie dem Statthalter falsche Auskunft von den Vermögensverhältnisse der Kandidaten gegeben haben, mussten sie nur dann haften, wenn sie es aus Arglist oder aus grober Fahrlässigkeit getan haben. Für die leichte Fahrlässigkeit hat sie die Haftung also nicht getroffen. Bei der Nomination des ungeeigneten Pflegers behauptet zwar Ulpian nur soviel, dass die Magistrate auch in dem Fall haften, wenn selbst der Statthalter den Pfleger bestellt, es kann aber - wegen der Parallelen zwischen der Vormundschaft und der Pflegeschaft - angenommen werden, dass sie auch in diesem Fall nur dann haften mussten, wenn sie arglistig oder mit grober Fahrlässigkeit gehandelt haben.

Demgegenüber kann aus den folgenden Fragmenten darauf gefolgert werden, dass in solchen Fällen, wo der Munizipalmagistrat selbst die tutoris datio vorgenommen hat, haftete er nicht nur für das dolus und die culpa lata, sondern auch für die leichte Fahrlässigkeit (culpa levis), ${ }^{101}$ die ganz bestimmt auch durch den Begriff des „omne periculum" einbegriffen wurde:

101 Vgl. Karlowa 1855, 596. 
D. $27,8,4$

Ulpianus 3 disp.

„Non similiter tenentur heredes magistratuum, ut ipsi tenentur: nam nec heres tutoris neglegentiae nomine tenetur. Nam magistratus quidem in omne periculum succedit, heres ipsius dolo proximae culpae succedaneus est."

Ulpian stellt fest, dass die Erben des Magistrats nicht genauso haften, wie der Magistrat selbst. Die Erben des Vormundes haften ja nicht für die Fahrlässigkeit. Der Magistrat muss zwar in die volle Haftung (omne periculum) eintreten, auf seine Erben geht aber die Haftung nur für solche Fahrlässigkeit über, die der Arglist sehr nahe liegt (also nur für die grobe Fahrlässigkeit).

Ulpian betont also, dass die Magistrate hinsichtlich der Vormundsbestellung für „omne periculum“ haften müssen. Zur Begriff des omne periculum könnte eventuell auch der casus gehören, aber die nächste Stelle beweist, dass die Magistrate für den Zufall, also für die unvorhersehbaren zukünftigen Ereignissen doch nicht verantwortlich gemacht werden konnten:

\section{D. $27,8,1,11$}

\section{Ulpianus 36 ad ed.}

„Si magistratus ab initio tutorem idoneum dedit et satis non exegit, non sufficit: quod si satis exegit et idoneum exegit, quamvis postea facultatibus lapsi sint tutores vel fideiussores, nihil est, quod ei qui dedit imputetur: non enim debent magistratus futuros casus et fortunam pupillo praestare."

Im Sinne der Stelle, wenn der Magistrat einen ursprünglich tauglichen Vormund bestellt hat, aber er keine Sicherheitsleistung verlangt hat, genügt das nicht. Wenn er aber eine Sicherheitsleistung verlangt, und einen tauglichen Vormund ausgewählt hat, ist dem Magistrat nichts vorzuwerfen, nicht einmal dann, wenn der Vormund oder die Bürgen ihr Vermögen später verloren haben. Da die Magistrate dem Mündel für die Zufälle und zukünftigen Vermögensverluste nicht einzustehen haben.

Im diesem Fall muss also der Magistrat dem Mündel für die Vormundsbestellung deswegen nicht haften, weil er mit hinreichender Sorgfalt den Vormund ausgewählt hat. Er hat nämlich einen tauglichen Vormund bestellt, und er hat auch für die Sicherheitsleistung (geeigneten Bürgen) gesorgt. Er hat so alles getan, was von ihm im Zusammenhang mit der tutoris datio zu erwarten war. Wenn der Vormund das Vermögen des Mündels doch nicht richtig verwaltete, woraus dem Mündel Schäden entstanden sind, kann das Mündel den Magistrat dementsprechend nicht einmal dann belangen, wenn es weder von dem Vormund noch von dessen Bürgen wegen ihrer 
nachträglichen Insolvenz keinen vollen Schadensersatz hat erlangen können. Es ist deswegen so, weil der Magistrat im Zusammenhang mit der Vormundsbestellung keinen - ihm vorwerfbaren - Fehler begangen hat. ${ }^{102}$ Ulpian schließt also in diesem Fall die Haftung der Magistrate für den casus, also für die unvorhersehbaren Ereignisse aus. ${ }^{103}$

Aufgrund der Quellen kann also darauf gefolgert werden, dass es zwischen der datio tutoris und der nominatio tutoris seitens der magistratus municipales hinsichtlich der Rechtsfolgen ein bedeutender Unterschied bestand: als nominatores hafteten sie nur für dolus und culpa lata, aber wenn sie selbst die Vormünder bestellten, hatten sie auch für die culpa levis einzustehen, die im Begriff des omne periculum inbegriffen war, aber für den casus mussten sie doch nicht haften. ${ }^{104}$

\section{Zusammenfassung}

Zusammenfassend kann also festgestellt werden, dass in solchen Fällen, wenn ein sui iuris Unmündiger weder einen tutor testamentarius noch einen tutor legitimus hatte, mussten die Magistrate sich um die Vormundsbestellung kümmern. Der Kreis der Magistrate, die zur tutoris datio befugt waren, wurde durch Gesetze, Senatsbeschlüsse und kaiserlichen Konstitutionen nach und nach erweitert. Die Magistrate hatten in Zusammenhang mit der Vormundsbestellung mit gehöriger Sorgfalt zu verfahren, um geeigneten Vormünder zu bestellen, und gegebenenfalls hatten sie sich auch um geeignete Sicherheitsleistung in Form einer Bürgenstellung (satisdatio) seitens der Vormünder zu kümmern.

Aufgrund der Quellen kann festgehalten werden, dass bestimmte Magistrate, so besonders die magistratus municipales dafür haften mussten, wenn sie entweder bei Vormundsbestellung (datio tutoris) oder in Zusammenhang mit der Vorschlag auf möglichen Vormünder (nominatio) nicht richtig verfahren sind, und ungeeigneten, bzw. insolventen Vormünder oder Bürgen nominierten, bestellten oder akzeptierten, oder gegebenenfalls gar keinen Vormund bestellten, oder von den Vormündern keine Sicherheitsleistung verlangten. Sie mussten aber dafür nur dann haften, wenn sie diese Fehler arglistig oder fahrlässig begangen haben. Und ihre Haftung war nur eine subsidiäre, also das Mündel konnte gegen sie eine Klage, die sogenannte actio subsidiaria erst dann erhalten, wenn es schon (mindestens teilweise) vergeblich versuchte, seine Schäden durch seine Vormünder und deren Bürgen ersetzen zu lassen, weil sie insolvent waren.

Die vorgeführten Normen bezüglich der römischen Vormundsbestellung sind wichtige historische Beispiele für die Haftung der staatlichen Beamten gegenüber Privatpersonen. So durch die Prüfung dieser Normen können solche Folgerungen gezogen werden, die auch für die modernen Zeiten interessant sein können.

102 Partsch 1908, 409.

103 LEVY 1915, 43.

104. Vgl. KarLOWA 1855, 596. 


\section{Literatur}

SZ = Zeitschrift der SavignyStiftung für Rechtsgeschichte. Romanistische Abteilung

Albertario, Emilio (1912): Dell' «actio subsidiaria〉 concessa al minore contro i magistrati (Studi dell' Istituto di Esercitazioni nelle scienze giuridiche e sociali della R Università di Pavia). Pavia, Mattei.

BenedeK, Ferenc - PóKecz Kovács, Attila (2017): Római magánjog. [Römisches Privatrecht] Budapest u. Pécs, Dialóg Campus Kiadó.

CARbone, Mariateresa (2017): Tutori magistratuali ed esonero dalla satisdatio in Gaio e in Giustiniano. Teoria e Storia del Diritto Privato, H. 10. 1-28.

CARBone, Mariateresa (2014): Satisdatio tutoris: Sull'obbligo del tutore di garantire per il patrimonio del pupillo. Milano, Giuffrè Editore.

CARbone, Mariateresa (2007): Un intervento del Senato in tema di libertas ed hereditas disposte per fideicommissum. In: Studi per Giovanni Nicosia II. Milano, Giuffrè Editore, 247-268.

Chevreau, Emmanuelle (2017): The Evolution of Roman Guardianship through the Mechanism of excusatio tutelae. In: Yiftach, Uri - Faraguna, Michele (Hrsg.): Ancient Guardianship: Legal Incapacities in the Ancient World. Jerusalem, 3-5.11.2013 (Legal Documents in Ancient Societies VI; GRAECA TERGESTINA STORIA E CIVILTÀ 4). Triest, EUT Edizioni Università di Trieste, 189-202.

Crawford, Michael Hewson (Hrsg.) (1996): Roman Statutes I. London, University of London, Institute of Classical Studies.

EсK, Werner (1979): Die staatliche Organisation Italiens in der hohen Kaiserzeit. München, C. H. Beck'sche Verlagsbuchhandlung.

Erman, H. (1894): Eine römisch-ägyptische Vormundschaftssache. SZ. H. 15. 241-255. DOI: https:// doi.org/10.7767/zrgra.1894.15.1.241

Fiebiger, Otto - Liebenam, Wilhelm (1905): Duoviri. In: Wissowa, Georg (Hrsg.): Paulys RealEncyclopädie der classischen Altertumswissenschaft (RE). Band 5, Stuttgart, J. B. Metzlersche Buchhandlung, 1798-1842.

Földi, András - Hamza, Gábor (2016): A római jog története és institúciói. [Geschichte und Institutionen des römischen Rechts] Budapest, Eszterházy Károly Egyetem Oktatáskutató és Fejlesztő Intézet.

Galaboff, Nikola Georgia (2016): Die Palingenesie der römischen Vormundschaftsgesetze. Frankfurt am Main, Peter Lang GmbH. DOI: https://doi.org/10.3726/978-3-653-06047-8

GlücK, Christian Friedrich (1829): Ausführliche Erläuterung der Pandecten, 30. Theils, 1. Abteil., Erlangen, Palm'schen Verlagsbuchhandlung.

Gómez-IGLesias CaSAL, Ángel (1997): Lex Ursonensis cap. 109: La tutela en la Lex Ursonensis y en la ley municipal. In: Studia Historica: Historia Antigua - Universidad de Salamanca, H. 15-16, 247-266.

GonzÁles, Julián - Crawford, Michael H. (1986): The lex Irnitana: A New Copy of the Flavian Municipal Law. The Journal of Roman Studies, H. 76, 147-243. DOI: https://doi.org/10.2307/300371

Grelle, Francesco (2006): La datio tutoris dei magistrati municipali. In: CAPOGRossi Colognesi, Luigi - Gabba, Emilio (Hrsg.): Gli Statuti Municipali. Pavia, Ius Press, 411-442.

Guzmán, Alejandro (1976): Dos estudios en torno a la historia de la tutela romana. Pamplona, Ediciones Universiad de Navarra. 
Havas, László - Németh, György - Szabó, Edit (2001): Római történeti kézikönyv. [Handbuch der römischen Geschichte] Budapest, Korona Kiadó.

ILLÉs, Imre Áron (2007): A lex Irnitana (egy Flavius-kori municipium törvénye) (Documenta Historica 77). Szeged, JATEPress.

JAKAB, Éva (2017a): Vormundschaft in lateinischen tabulae. In: YifTACH, Uri - FARAGUNA, Michele (Hrsg.): Ancient Guardianship: Legal Incapacities in the Ancient World. Jerusalem, 3-5. 11. 2013 (Legal Documents in Ancient Societies VI; GRAECA TERGESTINA STORIA E CIVILTÀ 4). Triest, EUT Edizioni Università di Trieste, 203-220.

JAKAB, Éva (2017b): Vis ac potestas. Gyámi vagyonkezelés a klasszikus római jogban. [Vis ac potestas. Vermögensverwaltung der Vormünder im klassischen römischen Recht] In: GöRöG, Márta - Hegedüs, Andrea (Hrsg.): Lege duce, comite familia: Ünnepi tanulmányok Tóthné Fábián Eszter tiszteletére, jogászi pályafutásának 60. évfordulójára. [Lege duce, comite familia: Festschrift für Eszter Tóth Fábián] Szeged, Iurisperitus, 199-211.

JАКАВ, Éva: Immunitás? Az állam kárfelelősségének történeti gyökereihez. [Immunität? Zu historischen Wurzeln der Schadensersatzhaftung des Staates] (kézirat)

JAnzsó, Miklós - SzABó, Ádám Ágoston (2009): Városi törvények a római köztársaság utolsó századából [Stadtgesetze aus den letzten Jahrhunderten der römischen Republik] (Documenta Historica 82). Szeged, JATEPress.

Karlowa, Otto (1855): Römische Rechtsgeschichte, Bd. I. Leipzig, Verlag von Veit \& Comp.

KASER, Max (1971): Das Römische Privatrecht, I. Abschnitt. München, C.H. Beck'sche Verlagsbuchhandlung.

KASER, Max - KnÜtel, Rolf - LoHSSE, Sebastian (2017): Römisches Privatrecht. München, Verlag C. H. Beck.

Knütel, Rolf - Kupisch, Berthold - Seiler, Hans Hermann - Behrends, Okko (Hrsg.) (2005): Corpus Iuris Civilis. Text und Übersetzung, IV. Digesten 21-27. Heidelberg, C. F. Müller Verlag.

Krause, Jens-Uwe (1995): Witwen und Weisen im Römischen Reich III. Rechtliche und soziale Stellung von Waisen. Stuttgart, Franz Steiner Verlag.

Kruse, Thomas (2017): Governmental Control of Guardianship over Minors in Roman Egypt. In: YiftaCh, Uri - Faraguna, Michele (Hrsg.): Ancient Guardianship: Legal Incapacities in the Ancient World. Jerusalem, 3-5.11.2013 (Legal Documents in Ancient Societies VI; GRAECA TERGESTINA STORIA E CIVILTÀ 4). Triest, EUT Edizioni Università di Trieste, 175-188.

KunKel, Wolfgang - Wittmann, Roland (1995): Staatsordnung und Staatspraxis der Römischen Republik, 2. Abschnitt, Die Magistratur. München, C. H. Beck'sche Verlagsbuchhandlung.

KüBLER, Bernhard (1918): Die Haftung für Verschulden bei kontraktsähnlichen und deliktsähnlichen Schuldverhältnissen, SZ. H. 39, 172-223. DOI: https://doi.org/10.7767/zrgra.1918.39.1.172

LAmberti, Francesca (1993): „Tabulae Irnitanae”: Municipalità e „ius Romanorum”. Napoli, Eugenio Jovene.

Lenel, Otto (1927): Das Edictum Perpetuum. Leipzig, Verlag von Bernhard Tauchnitz.

LEVy, Ernst (1915): Privatstrafe und Schadensersatz im klassischen römischen Recht. Berlin, Vahlen.

LEvy, Ernst (1916): Die Haftung mehrerer Tutoren. SZ. H. 37. 14-88. DOI: https://doi.org/10.7767/ zrgra.1916.37.1.14

Manfredini, Arrigo D. (1990): Papiniano il patruus e la conferma dei tutori da parte dei magistrati municipali (D. 26, 3, 5). Annali Univ. Ferrara - Scritti giuridici, Nuova Serie, Vol. IV, 51-60.

Mitteis, Ludwig (1908): Über die Kompetenzen zur Vormundsbestellung in den römischen Provinzen. SZ. H. 29. 390-403. DOI: https://doi.org/10.7767/zrgra.1908.29.1.390

MolnáR, Imre - JaKAB, Éva (2015): Római jog. [Römisches Recht] Szeged, Diligens. 
Mommsen, Theodor (1857): Die Stadtrechte der latinischen Gemeinden Salpensa und Malaca in der Provinz Baetica, nebst Nachträgen. Mit 1 lith. Tafel. Abhandlungen der PhilologischHistorischen Classe der Königlichen Sächischen Gesellschaft der Wissenschaften, Bd. 2., Leipzig, 361-507.

Mommsen, Theodor (1887): Römisches Staatsrecht, 1. Bd. Leipzig, Verlag von S. Hirzel.

NörR, Dieter (2001): Zur Palingenesie der römischen Vormundschaftsgesetze. SZ. H. 118., 1-72. DOI: https://doi.org/10.7767/zrgra.2001.118.1.1

Panero Oria, Patricia (2011): La datio tutoris en la Lex Irnitana cap. 29 Anuario de Historia del Derecho Español, 81, 973-996.

PARTSCH, Josef (1908): Der ediktale Garantievertrage durch receptum. SZ. H. 29, 403-422. DOI: https://doi.org/10.7767/zrgra.1908.29.1.403

PóKecz KovÁcs, Attila (2016): A principátus közjoga. [Öffentliches Recht des Prinzipats] Budapest u. Pécs, Dialóg Campus Kiadó.

PóKecz KovÁcs, Attila (2015a): A római közigazgatás Claudius uralkodása idején (Kr. u. 41-54). [Die römische Verwaltung während der Herrschaft von Claudius (41-45 n. Chr.)] JURA 21. évf. 1. sz. 100-110.

PóKeCz KovÁcs, Attila (2015b): Róma városának közigazgatása a principatus korában. [Die Verwaltung der Stadt Rom während des Prinzipats] JURA 21. évf. 2. sz. 100-108.

RAMPAzzo, Natale (2011): La «nominatio» e la responsabilità dei magistrati municipali. Index, 39, 363-378.

RudorfF, Adolf August Friedrich (1832): Das Recht der Vormundschaft, Bd. I. Berlin, Ferdinand Dümmler.

RudorfF, Adolf August Friedrich (1834): Das Recht der Vormundschaft, Bd. III. Berlin, Ferdinand Dümmler.

Sachers, Erich (1948): Tutela. In: Mittelhaus, Karl - Ziegler, Konrad (Hrsg.): Paulys RealEnciklopädie der classischen Altertumswissenschaft 2. Reihe (R-Z), 7. Bd. Tributum bis Valerius, (RE 7A/2). Waldsee (Württ.), Alfred Druckenmüller Verlag, 1497-1599.

Saller, Richard P. (1994): Patriarchy, Property and Death in the Roman Family. Cambridge, University Press. DOI: https://doi.org/10.1017/CBO9780511582998

Sciuto, Patrizia (2007): I limiti alia competenza dei magistrati municipali in materia di datio tutoris. In: Studi per Giovanni Nicosia VII. Milano, Giuffrè Editore, 349-392.

SCHUbert, Werner (1976): Walter Langhammer, Die rechtliche und soziale Stellung der Magistratus Municipales und der Decuriones in der Übergangsphase der Städte von sich selbst verwaltenden Gemeinden zu Vollzugsorganen des spätantiken Zwangsstaates (2. bis 4. Jahrhundert der römischen Kaiserzeit). Steiner-Verlag, Wiesbaden 1973. 325 S., (rec.). SZ. H. 93, 350-358. DOI: https://doi.org/10.7767/zrgra.1976.93.1.350

SIMSHÄUSER, Wilhelm (1973): Iuridici und Munizipialgerichtsbarkeit in Italien. München, Verlag von C.H. Beck.

SolAzzi, Siro (1917-1918): Sulla competenza dei magistrati municipali nella costituzione del tutore durante l'impero romano. Atti del Reale Istituto Veneto di scienze, lettere ed arti, 77, 1-24. (= Scritti di diritto romano, II, Napoli, Jovene, 1957, 211-228.)

Talamanca, Mario (1990): Istituzioni di diritto romano. Milano, Giuffrè Editore.

TAROzzI, Simona (2013): La petitio faciendi tutoris specialis di Gundihild in P. Ital. I, 7. In: BASSANELLI Sommariva, G. - TArozzi, Simona (Hrsg).: Ravenna Capitale, Territorialità e Personalità, Compresenza di diversi piani normativi. Ravenna, Maggioli, 107-126. 
ÚJVÁRI, Emese (2016): Contutores - a gyámok jogviszonya többes gyámság esetén a római jogban. [Contutores - das Rechtsverhältnis der Mitvormünder im römischen Recht] JURA 22. évf. 2. szám. 184-192.

WidAuer, Jasmin Maria (2014): Aspekte spätantiker Kindheit in der patristischen Literatur. Phil. Diss. Universität Wien. DOI: https://doi.org/10.25365/thesis.35226

Ziegler, Konrat - Sontheimer, Walther (Hrsg.) (1979): Der Kleine Pauly. Lexikon der Antike. München, Deutscher Taschenbuch Verlag. 